\title{
$\mathrm{SSD}($ Simultaneous Single Band Duplex) 시스템을 위한 효과적인 자기 간섭 제거 방법
}

\section{Effective Self-Interference Cancellation for SSD(Simultaneous Single Band Duplex) System}

\author{
안 창 영·유 흥 균 \\ Changyoung An $\cdot$ Heung-Gyoon Ryu \\ 요 약
}

본 논문에서는 동일 대역에서 동시에 전 이중 통신을 하기 위한 프레임 구조를 사용하는 터보 등화기를 결합한 SSD (Simultaneous Single band Duplex) 시스템을 제안한다. 본 논문에서는 자기 간섭 신호를 보다 효율적으로 제거하기 위하여 프레임 구조를 사용한다. 본 논문에서는 송수신 프레임 구조를 사용할 경우의 시스템의 특성을 분석하기 위하여 프레임 구조를 사용하지 않는 시스템과 성능을 비교하였다. 시뮬레이션 결과로 본 논문에서 제안하는 시스템은 프레임 구조를 사용하였을 경우, 프레임 구조를 사용하지 않았을 경우보다 더 좋은 성능을 내며, 프레임 구조를 사용하는 제안하는 시 스템은 더 적은 터보 등화기의 전역 반복으로 프레임 구조를 사용하지 않은 시스템과 유사한 성능을 낼 수 있는 것을 확인하였다.

\section{Abstract}

In this paper, we propose a $\operatorname{SSD}$ (Simultaneous Single band Duplex) system using turbo equalizer with frame structure for simultaneous full-duplex communication in single band. the proposed system uses frame structure for self-interference cancellation effectively. In this paper, performance of the proposed system with frame structure compares to performance of SSD system without frame structure to analysis performance of the proposed system with frame structure. Simulation results show that the performance of proposed system with frame structure is batter than performance of SSD system without frame structure when the number of global iterations of both system is same. Using proposed system with frame structure, we can verify that the performance like SSD system without frame structure by few global iteration of turbo equalizer.

Key words: Full-Duplex, Self-Interference, Turbo Equalizer, Frame Structure, Cancellation

$$
\text { I. 서 론 }
$$

스마트 폰 및 태블릿 $\mathrm{PC}($ Personal Computer) 등 다양한
모바일 단말기를 포함하여 삶의 질을 개선시키기 위한 무선 통신 기기들이 폭발적으로 증가하고 있으며, 그에 따른 상호 정보 교류를 위한 더 빠른 인터넷 접속과 멀티

「이 논문은 2013년도 정부(교육과학기술부)의 재원으로 한국연구재단의 지원을 받아 수행된 기초연구사업임(No.2013R1A2A2A01005849).」 충북대학교 전자공학과(Department of Electronic Engineering, Chungbuk National University)

• Manuscript received November 27, 2013 ; Revised January 13, 2014 ; Accepted January 15, 2014. (ID No. 20131127-118)

· Corresponding Author: Heung-Gyoon Ryu (e-mail: ecomm@cbu.ac.kr) 
미디어 콘텐츠 전송에 대한 요구가 증가하고 있다. 이렇 게 수많은 무선 통신 기기들의 더 빠른 정보 전송에 대한 요구를 충족시키기 위하여 더 많은 주파수 대역이 할당 되어 사용되어지고 있다. 이러한 이유로 현재 주파수 자 원이 매우 부족하며, 효율적인 주파수 자원 사용에 대한 관심이 높아지고 있다 ${ }^{[1]}$.

무선 통신 기기들은 각각의 시스템에 적합한 주파수 대역을 할당 받고, 이 주파수 대역을 이용하여 무선 통신 으로 정보를 교류한다. 또한, 상호 정보 교류를 위해 이중 통신 방식을 사용한다. 기존에는 이중 통신을 위하여 TDD (Time Division Duplex) 방식과 FDD(Frequency Division Duplex) 방식을 주로 사용하였다 [2],[3]. TDD 방식은 동일 주파수 대역에서 시간 도메인을 나누어 송신과 수신을 한다. FDD 방식은 서로 다른 주파수 대역을 동시에 이중 통신을 한다. TDD 방식은 송신과 수신 구간 사이에 보호 구간이 존재하며, 이러한 구간은 주파수 효율을 감소시킨 다. 또한, 하나의 대역에서 송신과 수신을 최대로 활용할 수 없다. FDD 방식은 이중 통신을 위하여 주파수 대역이 배로 사용하는 단점이 있다.

$\mathrm{TDD}$ 와 FDD 방식의 단점을 극복하여 주파수 효율을 향상시키기 위한 연구 중 하나로 SSD 시스템에 대한 연 구가 이루어지고 있다 ${ }^{[4],[5]}$. SSD 시스템은 동일 대역에서 동시에 전 이중 통신을 하는 시스템이다. 이러한 SSD 시 스템은 동일 대역에서 동시에 송수신을 하기 때문에, 자 국의 송신 신호가 자국의 수신기에 수신되어 자기 간섭 을 일으키는 문제가 있다. 따라서 이러한 자기 간섭 신호 는 적절한 자기 간섭 제거 기술을 이용하여 제거한다. 일 반적으로 잘 알려진 자기 간섭 제거 기술로는 $\mathrm{RF}$ (Radio Frequency) Cancellation과 Digital Cancellation이 있다 ${ }^{[6,[7]}$. $\mathrm{RF}$ Cancellation은 RF 영역에서 자기 간섭 신호를 감쇄시 키는 방법이고, Digital Cancellation은 수신기의 $\mathrm{ADC}$ 이후 에 디지털 영역에서 자기 간섭 신호를 제거하는 방법이 다. Digital Cancellation은 자국의 송신기에서 자국의 수신 기로 다중 경로를 통해 되돌아오는 다중 경로 자기 간섭 신호 성분과 RF Cancellation 이후 남은 자기 간섭 신호 성 분을 추정하여 제거한다. Digital Cancellation에는 일반적 으로 적응 알고리즘이 사용되는데, 이러한 적응 알고리즘 은 자기 간섭 신호 성분만 있을 경우, 자기 간섭 신호를
가장 잘 추정한다. 그렇기 때문에 상대국의 신호와 자기 간섭 신호가 동시에 수신되면 자기 간섭 신호를 명확하 게 추정할 수 없고, 그에 따라 Digital Cancellation에서 자 기 간섭 제거 능력은 감소하게 된다. 이러한 문제점은 송 수신 프레임 구조를 사용하여 해결할 수 있다. RF Cancellation 이후 Digital Cancellation에서 더욱 명확하게 자기 간섭 신호를 추정할 수 있도록 SSD 방식으로 통신을 하 기 전에 자기 간섭 신호 추정을 위한 프레임 구간을 할당 한다 ${ }^{[8]}$. 즉, 자기 간섭 신호 성분만 존재하는 프레임 구간 을 만들고, 그 구간에서 Digital Cancellation을 하기 위해 필요한 자기 간섭 신호 성분을 추정한다. 그 다음, 자기 간섭 신호 성분이 명확하게 추정된 후에 SSD 방식으로 통신을 한다.

본 논문에서는 동일 대역에서 동시에 전 이중 통신을 하는 SSD 시스템의 성능을 더욱 향상시키기 위하여 프레 임 구조를 사용하고, 터보 등화기를 결합한 SSD 시스템 을 제안하며, 제안하는 시스템이 프레임 구조를 사용했을 경우와 사용하지 않았을 경우에 성능을 분석하여 프레임 구조를 사용했을 경우 제안하는 SSD 시스템에 사용하는 터보 등화기의 더 적은 반복으로도 좋은 성능을 낼 수 있 음을 확인한다.

\section{II. 시스템 모델}

본 논문에서 제안하는 시스템은 단일 반송파를 사용하 고, 동일 대역에서 동시에 전 이중 통신을 하는 시스템이 다. 또한, 본 논문에서는 제안하는 시스템의 성능을 향상 시키기 위하여 터보 등화기와 프레임 구조를 사용한다.

그림 1 은 제안하는 동일 대역 동시 전 이중 통신 시스 템의 구성을 나타낸다. 제안하는 시스템은 단일 반송파를 사용하는 시스템으로 QPSK 변조를 사용하여 신호를 전 송한다. 본 논문에서 제안하는 시스템은 동일 대역에서 동시에 전 이중 통신을 하기 때문에, 자국의 송신 신호가 자국의 수신기에 간섭을 일으킬 수 있다. 이러한 자기 간 섭신호는 상대국에서 보낸 수신 신호에 비하여 매우 크 기 때문에, 일반적인 방법으로 수신을 할 경우 상대국에 서 보낸 수신 신호가 모두 왜곡되어 상대국의 정보를 수 신할 수 없다. 특히, 이렇게 큰 크기의 신호가 RF Chain에 인가될 경우 수신기의 가장 앞단에 구성되어 있는 LNA 


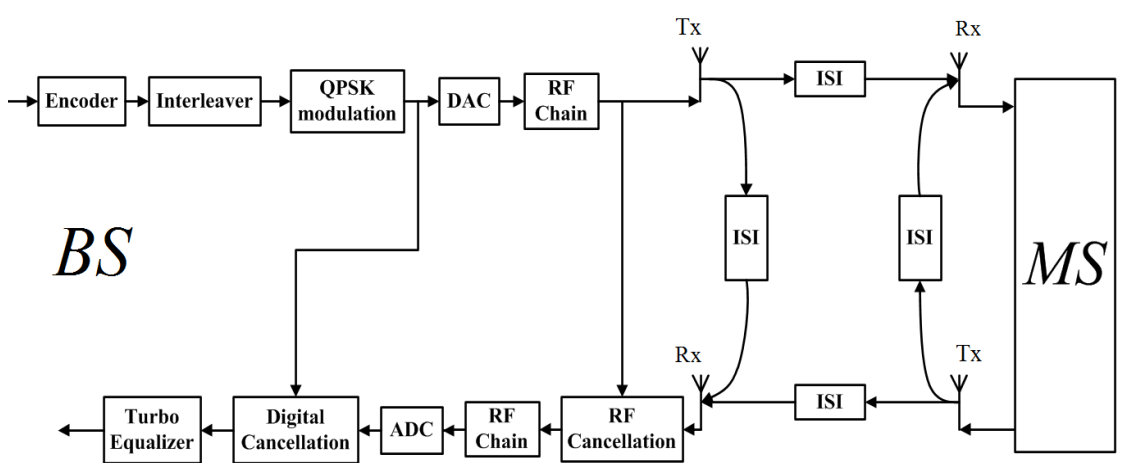

그림 1. 제안하는 동일 대역 동시 전 이중 통신 시스템의 블록도

Fig. 1. Block diagram of proposed simultaneous single band full duplex system.

가 손상되거나 포화되어 상대국의 어떠한 신호도 수신할 수 없는 상황이 발생할 수 있다. 이러한 이유로 동일 대역 에서 동시에 전 이중 통신을 하기 위해서는 이러한 문제 를 발생시키는 자기 간섭 신호를 효과적으로 제거하는 시스템이 추가적으로 필요하게 된다. 따라서 본 논문에서 제안하는 시스템은 일반적인 송수신 구조에 자기 간섭 제거를 위한 RF Cancellation 및 Digital Cancellation 과정 이 추가적으로 구성되어 있다. 또한, 본 논문에서 제안하 는 시스템은 잔류 자기 간섭 신호에 의한 정보 비트의 오 류를 복원하고, 상대국에서 보낸 수신 신호의 등화 성능 을 향상시켜 시스템의 신뢰도를 더욱 높이기 위하여 터 보 등화기를 사용한다. 터보 등화기는 등화기와 디코더를 연계하여 반복 등화를 함으로써 등화 성능을 향상시킨다.

시스템의 정보 신호 흐름을 보면 우선 정보 비트 열은 인코더를 통과한다. 인코더는 통신 시스템의 신뢰도 향상 시키기 위하여 수신 후에 정보 비트에 오류가 있을 경우, 이를 정정하기 위하여 사용한다. 인코딩 방법에는 여러 가지 코드가 사용된다. 본 논문에서는 콘볼루션 코드를 사용하는 인코더를 사용하여 시스템을 구성하였다. 콘볼 루션 코드는 하나의 비트를 출력하기 위해서 이전에 출 력된 여러 비트와 연관시켜 출력한다. 즉, 수신기에서는 이러한 연관된 성질을 이용하여 정보 비트에 발생한 오 류를 정정하게 된다. 정보 비트가 인코더를 거친 후 인터 리버를 거치게 된다. 인터리버는 정보 비트의 전송 순서 를 바꾸어 특정 부분에 오류가 집중되는 것을 방지한다. 인코딩된 신호는 부분적으로 발생한 비트 오류에 대해서
는 복구가 가능하지만, 비트 오류가 특정 부분에 집중된 다면 정보 비트들 간에 연관 성질이 손상되어 비트 오류 정정 성능이 매우 감소된다. 따라서 특정 부분에 집중적 으로 비트 오류가 발생하는 것을 막기 위해 순서를 특정 규칙에 의해 바꾸어 전송하게 된다. 인터리버를 거친 후 의 정보 비트는 $\mathrm{QPSK}$ 변조가 된 후 $\mathrm{DAC}$ 를 거쳐 아날로 그 신호로 변환된다. 변환된 아날로그 신호는 RF Chain을 거쳐 안테나를 통해 송신된다. 송신된 신호는 다중 경로 환경을 통해 상대국의 수신기에 수신된다. 또한, 자국의 수신기에도 다중 경로를 거쳐 수신되어 자기 간섭을 일 으킨다. 이러한 자기 간섭 신호는 가장 먼저 RF Cancellation 과정을 통해 그 크기를 감쇄시킨다. 그 다음, $\mathrm{RF}$ Chain을 통과한 후에 $\mathrm{ADC}$ 를 거쳐 디지털 영역에서 $\mathrm{Di}-$ gital Cancellation 과정을 통해 RF Cancellation 이후에 남 은 잔류 자기 간섭 신호 성분과 다중 경로 자기 간섭 신 호 성분을 추가적으로 감쇄시킨다. RF Cancellation과 Digital Cancellation을 통해 자기 간섭 신호를 최대한 감쇄시 킨 후에 터보 등화기를 통해 상대국과 자국 간의 다중 경 로 채널에 의한 ISI 효과를 등화하여 상대국의 정보 신호 를 수신한다. 특히 시스템의 자기 간섭 신호 제거 효과를 더욱 높이기 위하여 자국에서 송수신을 할 때 프레임 구 조를 사용하여 송수신을 하였다.

그림 1에서 $\mathrm{BS}$ 와 $\mathrm{MS}$ 는 각각 base station과 mobile station을 의미한다. 본 논문에서 제안하는 시스템에서 $\mathrm{MS}$ 측 의 시스템은 $\mathrm{BS}$ 측의 시스템과 동일하게 $\mathrm{RF}$ Cancellation 과 Digital Cancellation이 구성되어 있으며, 터보 등화기를 
통해 $\mathrm{BS}$ 측에서 $\mathrm{MS}$ 측 사이에 다중 경로에 의해 발생하는 ISI에 의한 신호 왜곡을 등화한다.

\section{III. 자기 간섭 제거 및 터보 등화기}

\section{3-1 RF Cancellation}

RF Cancellation은 수신기의 가장 앞단에서 자국 송신 기에서 자국 수신기로 최단거리를 거쳐 영향을 미치는 자기 간섭 신호를 제거한다. 최단 거리를 거치는 직접 자 기 간섭 신호의 경우 그 크기가 매우 크다. 즉, RF Chain 으로 진행하는 직접 자기 간섭 신호의 크기를 최초로 감 쇄시키는 역할을 한다. RF Cancellation은 특정한 신호와 크기는 같고, 위상이 $180^{\circ}$ 인 신호가 서로 합쳐질 경우 두 신호가 서로 상쇄되는 원리를 이용한다.

그림 2는 본 논문에서 제안하는 시스템에서 사용하는 RF Cancellation 방법을 나타낸다. 자국 송신기의 RF 영역 의 신호를 위상 천이기와 감쇄기를 이용하여 자국 송신 기에서 송신되어 자국 수신기로 수신되는 자기 간섭 신 호와 크기는 같고, 위상이 반대인 신호를 생성한다. 그 다 음, 생성된 이 신호를 자국 수신기의 RF Chain 앞에서 결 합기를 이용하여 결합하여 줌으로써 자기 간섭 신호가 수신 안테나에 인가될 때 역 위상 신호 또한 합성되어 자 기 간섭 신호를 상쇄시킨다.

\section{3-2 Digital Cancellation}

Digital Cancellation은 수신기에서 $\mathrm{ADC}$ 를 거친 후에 디

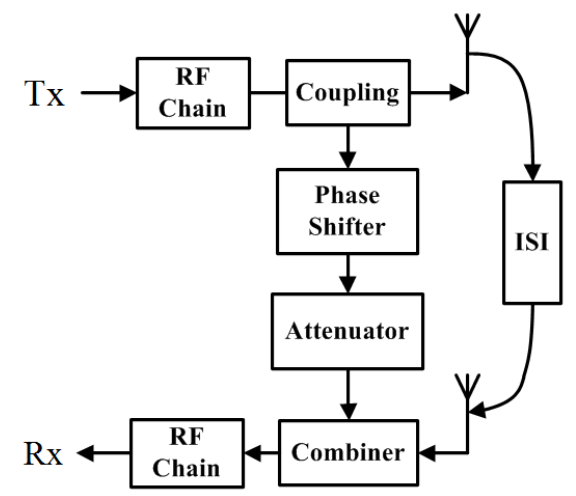

그림 2. RF cancellation의 블록도

Fig. 2. Block diagram of RF cancellation.

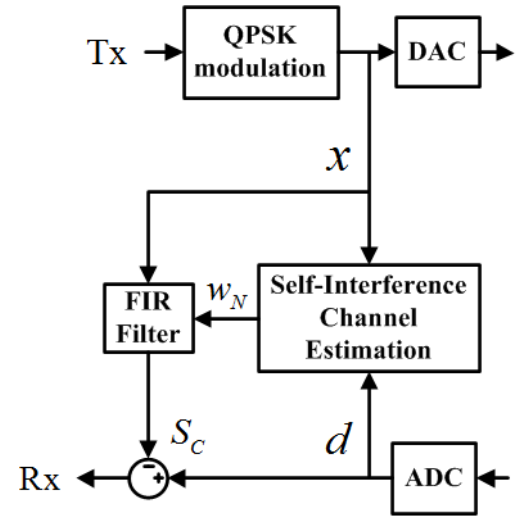

그림 3. Digital cancellation의 블록도

Fig. 3. Block diagram of digital cancellation.

지털 영역에서 자기 간섭 신호를 제거 하는 방법이다. Digital Cancellation은 자국 송신기에서 자국 수신기로 다 중 경로를 거쳐 되돌아오는 다중 경로 자기 간섭 신호 성 분과 RF Cancellation에서 남은 잔류 자기 간섭 신호 성분 을 제거한다.

그림 3은 본 논문에서 제안하는 시스템에서 사용하는 Digital Cancellation 방법을 나타낸다. 디지털 영역에서 자 기 간섭 신호를 제거하는 Digital Cancellation은 자기 간섭 신호를 추정하기 위하여 적응 알고리즘을 사용한다. 적응 알고리즘의 입력은 자국 송신기의 $\mathrm{DAC}$ 이전의 디지털 신호를 사용한다. 적응 알고리즘의 목표 신호는 자기 간 섭 신호가 포함된 자국 수신기의 $\mathrm{ADC}$ 이후의 신호를 사 용한다. 입력신호와 목표신호를 이용하여 입력 신호가 목 표신호와 같아지도록 하는 계수를 구하고, 이 계수를 FIR 필터에 적용시킨다. 그 다음, 입력 신호를 FIR filter에 통 과시키면 자기 간섭 신호와 유사한 신호를 생성하게 되 며, 생성된 신호를 자기 간섭 신호가 포함된 신호에서 빼 주어서 자기 간섭 신호를 제거한다.

본 논문에서는 적응 알고리즘으로 $\mathrm{LMS}$ (Lease Mean Square) 알고리즘을 사용하며, 이 알고리즘을 이용하여 자기 간섭 신호를 추정한다. LMS 알고리즘은 추정된 계 수를 사용한 필터의 출력과 목표 신호와의 오차를 최소 화 하도록 계수를 갱신하여 입력 신호를 목표 신호와 유 사해지도록 하는 계수를 구하는 알고리즘이다. LMS 알 고리즘에서 오차에 대한 식은 다음과 같다[9]. 


$$
e_{k}=d_{k}-W_{k}^{H} X_{k}
$$

여기에서 $d_{k}$ 는 목표 신호로 그림 3에서 $d$ 의 신호를 나타 낸다. $X_{k}$ 는 입력신호로 그림 3 에서 $x$ 의 신호를 나타낸 다. $W_{k}^{H}$ 는 자기 간섭 신호 성분을 추정한 계수로, 그림 3에서 FIR filter에 적용되는 계수 값을 나타낸다. LMS 알 고리즘은 이 추정된 계수 값 $W_{k}^{H}$ 을 지속적으로 갱신하 여 필터를 통과한 출력 신호와 목표 신호와의 오차가 최 소가 되도록 한다. 추정된 계수를 갱신하는 식은 다음과 같다 ${ }^{[9]}$.

$$
W_{k+1}=W_{k}+2 \mu e_{k} X_{k}
$$

여기에서 $\mu$ 는 스텝 크기로 계수를 갱신하는 간격을 나타 내는 상수 값이다.

\section{3-3 프레임 구조}

본 논문에서는 제안하는 시스템은 Digital Cancellation 에서 RF Cancellation 이후의 잔류 자기 간섭 신호 성분과 다중 경로 자기 간섭 신호 성분을 추정하여 제거한다. 적 응 알고리즘을 이용하여 자기 간섭 신호성분을 추정할 때 상대국의 신호가 있을 경우, 자기 간섭 신호를 추정하 는 것이 어려워진다. 즉, 자기 간섭 신호만이 수신될 경 우, 자기 간섭 신호를 더 명확하게 추정할 수 있다. 이러 한 이유로 자기 간섭 신호를 더욱 효과적으로 제거하기 위하여 새로운 프레임 구조를 사용한다.

그림 4는 본 논문에서 사용하는 프레임 구조를 나타낸 다. 본 논문에서는 그림 4 의 프레임 구조를 사용하여 더

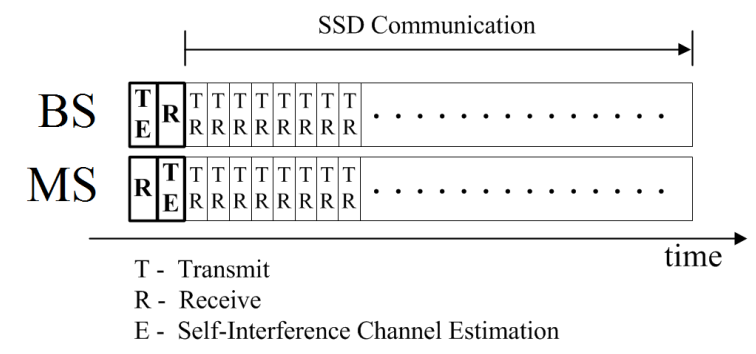

그림 4. 자기 간섭 채널 추정을 위한 시간 도메인 프레 임 구조

Fig. 4. Frame structure for estimation of self-interference channel in time domain.
욱 효율적으로 자기 간섭 신호를 추정할 수 있도록 하였 다. 우선 $\mathrm{BS}$ 에서 신호를 전송한다. $\mathrm{BS}$ 에서 최초 신호를 전송할 경우, $\mathrm{MS}$ 에서는 송신을 하지 않고 신호를 수신한 다. 첫 번째 단계에서는 $\mathrm{BS}$ 에서만 신호를 송신하기 때문 에 자기 간섭 신호에 상대국에서 보낸 수신 신호가 포함 되지 않고, 이 시점에서 $\mathrm{BS}$ 은 자기 간섭 신호를 추정하게 된다. 첫 번째 프레임에서 $\mathrm{BS}$ 의 자기 간섭 신호 추정이 완료된 후, 그 다음 프레임에서는 MS에서만 신호를 송신 한다. 이 시점에서는 MS의 자기 간섭 신호를 추정한다. 두 번째 프레임 구간에서는 MS이 송신과 자기 간섭 신호 추 정을 하고 $\mathrm{BS}$ 에서는 수신만을 한다. 이러한 방식으로 동 일 대역에서 동시에 전 이중 통신을 하기 전에 자기 간섭 신호 외에 다른 신호 성분이 없도록 하여 자기 간섭 신호 를 더욱 효율적으로 추정한다. 자기 간섭 신호를 더 명확 하게 추정할수록 더욱 자기 간섭 신호를 명확하게 제거 하고, 시스템의 성능을 더욱 향상시킬 수 있다.

\section{3-4 터보 등화기}

본 논문에서 제안하는 시스템은 전 이중 통신에서 발 생하는 비트 오류를 정정하고, 상대국의 채널 상황이 좋 지 않을 경우 이를 효과적으로 등화하기 위하여 터보 등 화기를 사용한다. 터보 등화는 수신기에서 등화기와 디코 더를 연계하여 결합한 뒤, LLR(Log-Likelihood Ratio)값을 반복적으로 순환시켜 시스템의 성능을 향상시키는 등화 방법이다 ${ }^{[10]}$.

그림 5 는 본 논문에서 제안하는 시스템에서 사용하는 등화기인 터보 등화기의 구조를 나타낸다. 터보 등화기는 내부의 등화기, 디인터리버, 디코더 그리고 인터리버로 구성되어 있다 ${ }^{[10]}$. 본 논문에서는 터보 등화기 내부의 등 화기로 $\mathrm{MAP}$ (maximum a posteriori) 등화기를 사용한다.

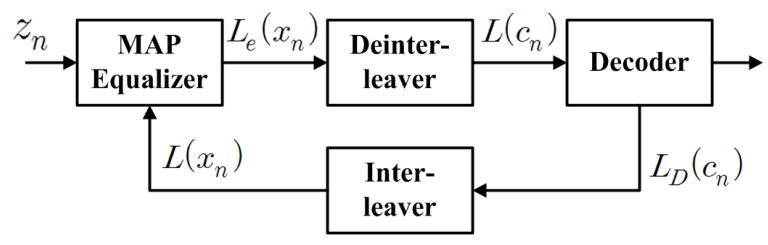

그림 5. 터보 등화기의 구성도

Fig. 5. Block diagram of turbo equalizer. 
$\mathrm{MAP}$ 등화기는 일반적으로 최적의 등화 성능을 갖는 것 으로 알려져 있다. MAP 등화기의 출력은 다음과 같이 표 현된다 ${ }^{[10]}$.

$$
\begin{aligned}
L_{e}\left(x_{n}\right) \cong & \ln \frac{P\left(x_{n}=+1 \mid z_{1}, \ldots, z_{K_{c}}\right)}{P\left(x_{n}=+1 \mid z_{1}, \ldots, z_{K_{c}}\right)} \\
& -\log \frac{P\left(x_{n}=+1\right)}{P\left(x_{n}=-1\right)}
\end{aligned}
$$

MAP 등화기의 출력은 사후 LLR 값과 사전 LLR 값의 차로 나타내어진다. 식 (3)에서 $z_{n}$ 은 수신 받은 심볼을 나타낸다. 사전 확률 $L\left(x_{n}\right)$ 은 $x_{n}$ 의 발생 확률에 대한 사전 정보를 나타낸다. $L\left(x_{n}\right)$ 은 디코더로부터 구해진다. 초기 등화 단계에서는 사전 정보가 없기 때문에 $L\left(x_{n}\right)$ 는 0 이 된다.

터보 등화기에서 디코더는 MAP 디코더를 사용하며, $\mathrm{MAP}$ 디코더는 사후 확률을 코드 비트 LLR 값 $L\left(c_{n}\right)$ 을 이용하여 연산한다. MAP 디코더의 출력은 다음과 같이 표현된다 ${ }^{[10]}$.

$$
\begin{aligned}
L_{D}\left(c_{n}\right)= & \ln \frac{P\left(c_{n}=+1 \mid L\left(c_{1}\right), \ldots, L\left(c_{K_{c}}\right)\right)}{P\left(c_{n}=-1 \mid L\left(c_{1}\right), \ldots, L\left(c_{K_{c}}\right)\right)} \\
& -\ln \frac{P\left(c_{n}=+1\right)}{P\left(c_{n}=-1\right)}
\end{aligned}
$$

여기에서 $\mathrm{MAP}$ 등화기의 출력 $L_{e}\left(x_{n}\right)$ 는 $\mathrm{MAP}$ 디코더에 서 사전 LLR 값 $L\left(c_{n}\right)$ 으로 고려된다. $L\left(c_{n}\right)$ 는 등화기의 출력이 디인터리버를 통과한 후의 신호이다. 식 (4)를 이 용하여 구해진 MAP 디코더의 출력은 인터리버를 거친 후 MAP 등화기로 궤환된다. 터보 등화기는 이러한 궤환 을 반복함으로써 등화 성능을 향상시킨다. 마지막으로 디 코더에서는 최종적으로 정보 비트를 추정하여 출력한다. $\mathrm{MAP}$ 디코더의 출력에 대한 식은 다음과 같이 나타낸 다 ${ }^{[10]}$.

$$
\hat{b_{i}}=\operatorname{argmax}_{b \in\{0,1\}} P\left(b_{i}=b \mid L\left(c_{1}\right), \ldots, L\left(c_{K_{c}}\right)\right)
$$

\section{IV. 시뮬레이션 및 분석}

본 논문에서는 제안하는 터보 등화기를 결합한 $\mathrm{SSD}$ 시 스템의 송수신 프레임 구조의 사용에 대한 성능을 비교
표 1. 시뮬레이션 환경

Table 1. Simulation parameters.

\begin{tabular}{|c|c|}
\hline Modulation & QPSK \\
\hline Adaptive algorithm & LMS \\
\hline Number of taps & 32 \\
\hline Step size & 0.001 \\
\hline Channel & Proakis B \\
\hline Channel coding & Convolutional code \\
\hline Code rate & $3 / 4$ \\
\hline Equalizer & Turbo equalizer \\
\hline Number of iterations & $0,1,2,3,4$ \\
\hline Carrier frequency & $2.5 \mathrm{MHz}$ \\
\hline
\end{tabular}

평가하기 위하여 Simulink 시뮬레이션 프로그램을 이용 하여 시스템을 구성하였다. 시뮬레이션을 위한 세부 사항 은 다음과 같다.

본 논문에서 자국 송신기에서 자국 수신기로 자기 간 섭 신호가 진행할 때 안테나간 거리에 의해서 약 $30 \mathrm{~dB}$ 의 감쇄가 일어나는 상황을 고려하였다. 본 논문에서 제안하 는 시스템은 RF Cancellation을 하기 위한 위상 천이기에 $0.5^{\circ}$ 의 위상 천이 오차가 있는 환경을 고려하였다. 또한, RF Cancellation의 감쇄기는 $-29.5 \mathrm{~dB}$ 의 크기를 감쇄시키 도록 시스템을 구성하였다. 제안하는 시스템은 Digital Cancellation을 위한 적응 등화기로 LMS 알고리즘을 사용 하였으며, LMS 알고리즘에 사용되는 filter의 탭 개수는 32 개로 하였고, 스텝 크기는 0.001 로 하였다. 본 논문에서 는 제안하는 터보 등화기를 결합한 시스템이 송수신 프 레임 구조를 사용하였을 경우와 송수신 프레임 구조를 사용하지 않을 경우의 시스템 성능을 비교하였다. 제안하 는 시스템은 그림 4의 프레임 구조와 같이 $\mathrm{BS}$ 측에서 먼 저 송신하고, 그 다음 $\mathrm{MS}$ 측에서 송신을 한 다음 동시에 통신하도록 시스템을 구성하였다. 본 논문에서는 터보 등 화기의 반복 횟수를 $0 \sim 4$ 번까지 반복시켜 시스템의 성능 신뢰도를 최대한 향상시켰으며, 프레임 구조를 이용하여 자기 간섭 신호의 추정을 더욱 명확하게 할 수 있도록 하 였다.

그림 6은 송신 신호의 스펙트럼을 나타낸다. 본 논문에 서 제안하는 시스템의 송신 신호 크기의 기준을 $20 \mathrm{~dB}$ 로 


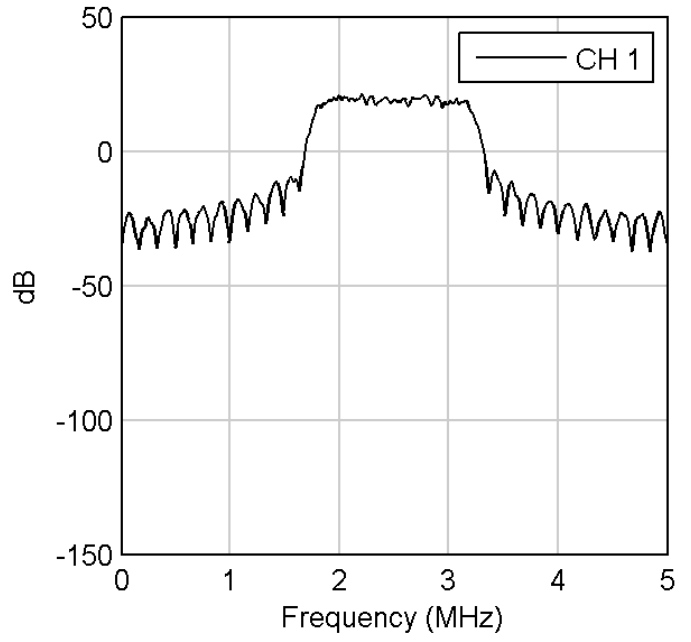

그림 6. 송신 신호의 스펙트럼

Fig. 6. Spectrum of transmit signal.

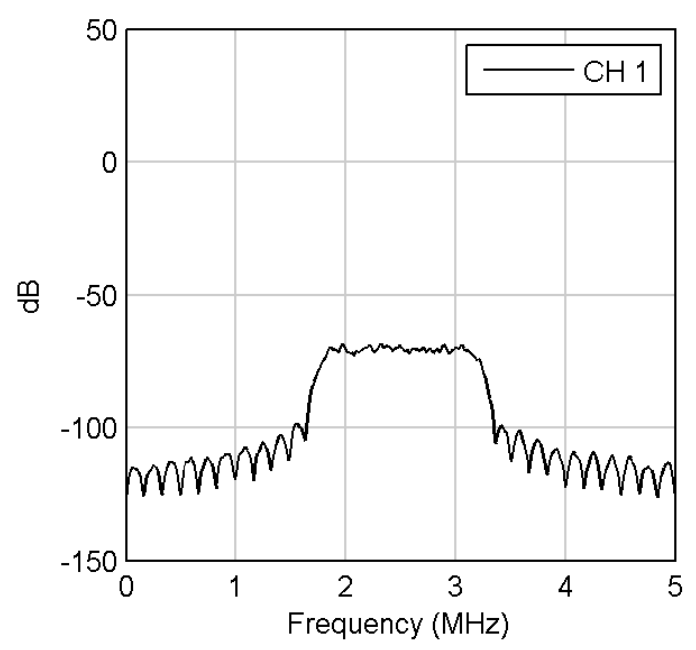

그림 7. 수신 신호의 스펙트럼

Fig. 7. Spectrum of receive signal.

\section{고려하였다.}

그림 7은 상대국에서 보낸 수신 신호의 스펙트럼을 나 타낸다. 자국과 상대국에서는 모두 그림 6과 같이 $20 \mathrm{~dB}$ 의 신호 크기로 신호를 송신하며, 상대국 송신기에서의 송신 신호는 신호가 전파될 때 거리에 의에 그 크기가 감 쇄되어 자국 수신기로 도달할 때 $-70 \mathrm{~dB}$ 의 크기로 도달 하는 환경을 고려하였다.

즉, 자국 송신 신호의 크기와 상대국에서 보낸 수신 신 호의 크기는 약 $90 \mathrm{~dB}$ 의 차이를 갖게 된다. 따라서 상대

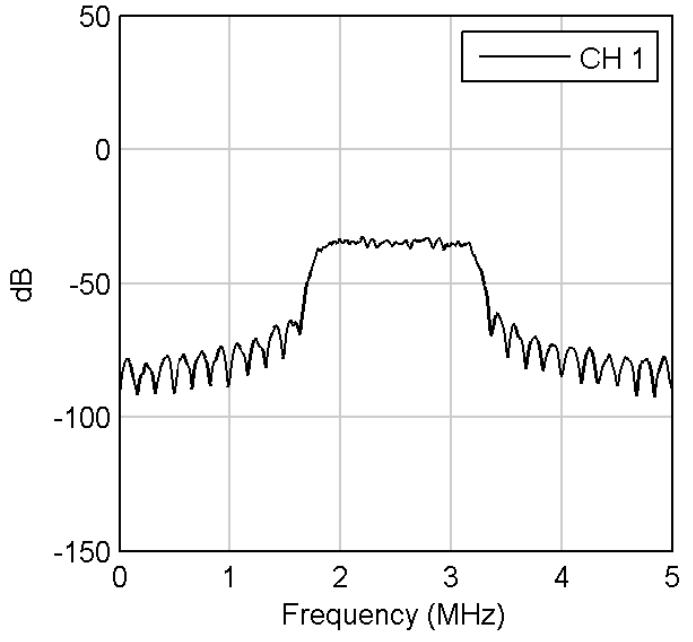

그림 8. RF cancellation 이후 신호의 스펙트럼

Fig. 8. Spectrum of signal after RF cancellation.

국에서 보낸 수신 신호에 비하여 약 $90 \mathrm{~dB}$ 큰 신호가 자 기 간섭을 일으키기 때문에 자기 간섭 신호 제거를 하지 않으면 상대국의 신호가 완전히 왜곡되어 어떠한 정보도 수신할 수 없다.

그림 8은 제안하는 시스템이 RF Cancellation을 거친 후 의 신호 스펙트럼을 나타낸다. RF Cancellation 이후의 신 호 크기가 약 $-35 \mathrm{~dB}$ 인 것을 확인할 수 있다. 즉, 자국 송신기에서 $20 \mathrm{~dB}$ 의 크기를 갖는 송신 신호가 전파되고, 자국 수신기에 자기 간섭을 일으킬 때, 자국 송신기와 자 국 수신기 간의 거리에 의해서 $30 \mathrm{~dB}$ 감쇄되는 환경을 고 려하였기 때문에, 자국 수신기에 간섭을 일으키는 자기 간섭 신호의 크기는 약 $-10 \mathrm{~dB}$ 가 된다. 여기에서 $\mathrm{RF}$ Cancellation을 거치면 추가적으로 $-25 \mathrm{~dB}$ 를 감쇄시켜 신 호 크기는 $-35 \mathrm{~dB}$ 가 된다.

그림 9는 프레임 구조를 사용하지 않는 상황에서 터보 등화기 반복에 대한 제안하는 시스템의 성능을 나타낸다. 시스템의 성능은 터보 등화기의 전역 반복이 3회 되었을 때 거의 포화되어 전역 반복 횟수가 증가하여도 성능의 개선이 더 이상 크게 일어나지 않은 것을 확인할 수 있다. 제안하는 시스템은 프레임 구조를 사용하지 않는 상황에 서 터보 등화기의 전역 반복이 3 회일 경우 $8 \mathrm{~dB}$ 에서 약 $4 \times 10^{-4}$ 의 성능을 내는 것을 확인할 수 있다.

그림 10 은 프레임 구조를 사용하는 상황에서 터보 등 


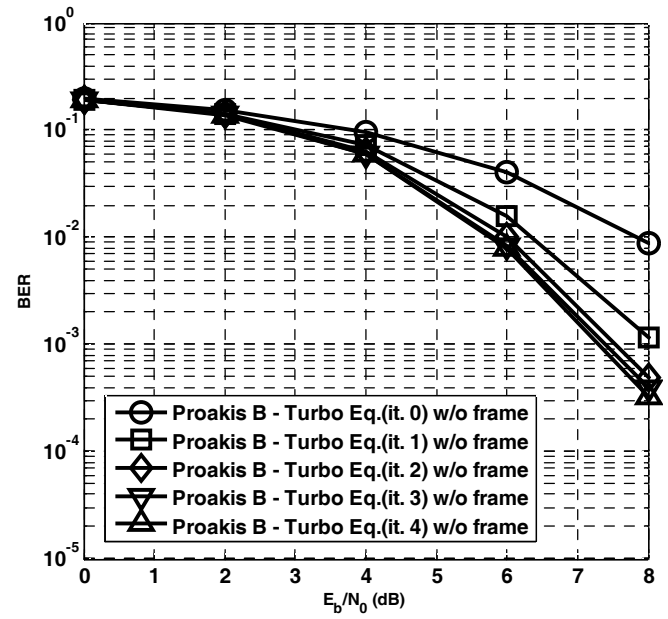

그림 9. 프레임 구조를 사용하지 않은 제안하는 시스템 의 성능

Fig. 9. BER performance of proposed system without frame structure.

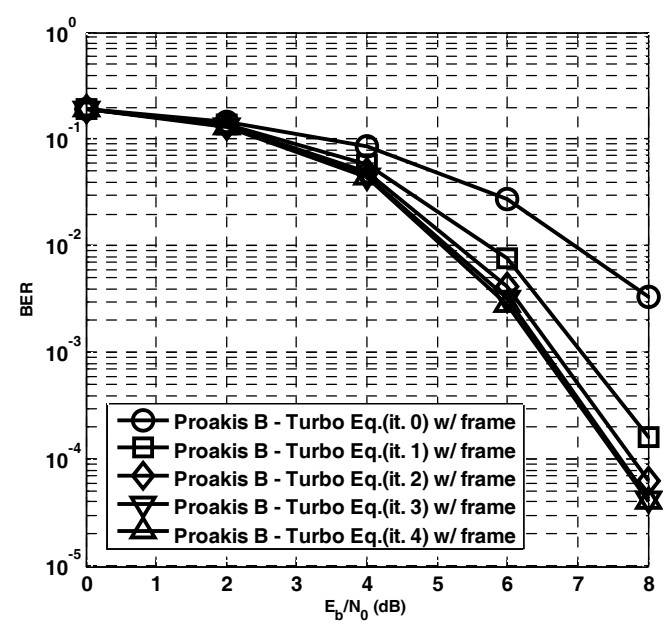

그림 10. 프레임 구조를 사용하였을 경우 제안하는 시스 템의 성능

Fig. 10. BER performance of proposed system with frame structure.

화기 반복에 대한 제안하는 시스템의 성능을 나타낸다. 프레임 구조를 사용하는 환경에서 제안하는 시스템은 터 보 등화기의 전역 반복이 3회일 경우, 성능이 포화되어 더 이상 전역 반복이 증가하더라도 성능의 개선이 거의 나타나지 않는 것을 확인할 수 있다. 프레임 구조를 사용 하는 환경에서 제안하는 시스템은 터보 등화기의 전역

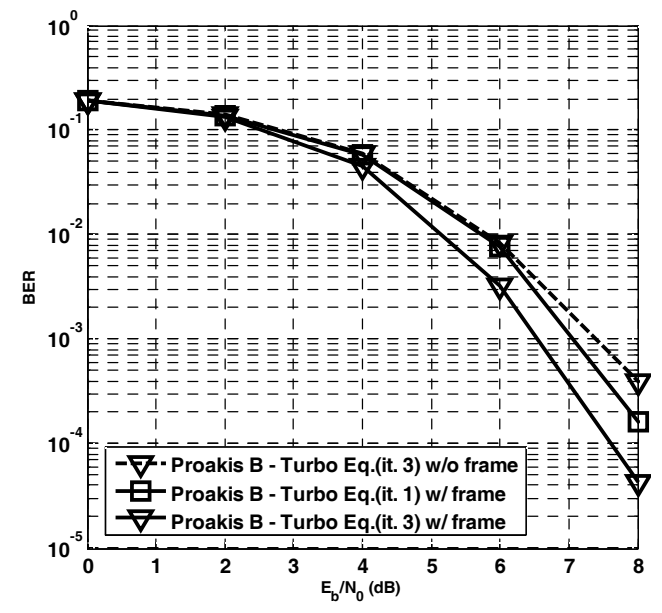

그림 11. 프레임 구조 유무에 따른 제안하는 시스템의 성 능 비교

Fig. 11. Comparison of BER performance of proposed system according to frame structure.

반복이 3 회일 경우, $8 \mathrm{~dB}$ 에서 약 $4 \times 10^{-5}$ 의 성능을 내 는 것을 확인할 수 있다.

그림 11은 제안하는 시스템이 프레임 구조를 사용하였 을 경우와 사용하지 않았을 경우의 성능 비교를 나타낸 다. 프레임 구조를 사용한 경우와 사용하지 않은 경우, 모 두 터보 등화기의 전역 반복이 3 회일 때 $4 \times 10^{-4}$ 의 성 능을 내는데, 약 $1 \mathrm{~dB}$ 의 성능 차이로 프레임 구조를 사용 하였을 경우 더 좋은 성능을 내는 것을 확인할 수 있다. 또한, 프레임 구조를 사용하였을 경우, 터보 등화기의 전 역 반복 1회 만으로도 프레임 구조를 사용하지 않았을 경 우 전역 반복이 3 회일 경우보다 더 좋은 성능을 내는 것 을 확인할 수 있다. 즉, 프레임 구조를 사용할 경우, 터보 등화기의 반복 횟수를 감쇄시켜 시스템의 복잡도를 감소 시킬 수 있는 것을 확인할 수 있다.

본 논문에서 제안하는 RF Cancellation과 프레임 구조 를 결합한 Digital Cancellation 그리고 열악한 채널 환경에 서 신뢰도 있는 통신을 보장하기 위하여 터보 등화기를 결합한 시스템은 RF Cancellation을 통하여 1차적으로 자 기 간섭 신호를 제거하고, Digital Cancellation을 하기 위 하여 프레임 구조를 사용함으로 인하여 잔류 자기 간섭 신호를 추정할 때 다른 신호 성분이 포함되지 않게 하여 보다 명확하게 잔류 자기 간섭 신호를 추정하고, 이를 통 
하여 자기 간섭 신호를 보다 효율적으로 제거할 수 있다. 이러한 시스템 구조는 프레임 구조를 통하여 터보 등화 기의 반복을 줄여 수신 신호를 등화 하는데 소모되는 시 간을 감소시켜 보다 고속의 데이터 통신을 하는데 유리 하다. 또한, 터보 등화기를 결합하여 채널 환경이 열악한 경우에도 통신 성능의 신뢰도를 보장하면서 동일 대역에 서 동시에 송수신을 할 수 있다. 즉, 제안하는 시스템은 높은 신뢰도를 갖는 전 이중 통신이 가능하다. 제안하는 시스템은 시간적인 구분 없이 송수신을 하여 데이터 전 송속도를 향상시킬 수 있으며, 동일 대역에서 동시에 송 수신이 가능하기 때문에 보다 효율적으로 주파수 자원을 활용할 수 있다. 즉, 대부분의 무선 통신 시스템에서 주파 수 효율과 데이터 전송 속도를 향상시킬 수 있다.

\section{$\mathrm{V}$. 결 론}

본 논문에서는 동일 대역에서 동시에 전 이중 통신을 하기 위한 프레임 구조를 사용하는 터보 등화기를 결합 한 SSD 시스템을 제안한다. 본 논문에서는 자기 간섭 신 호를 보다 효율적으로 제거하기 위하여 프레임 구조를 사용한다. 본 논문에서는 프레임 구조의 사용에 대한 제 안하는 시스템의 성능을 분석하기 위하여 Simulink 프로 그램을 이용하여 시스템을 구성하였다. 제안하는 시스템 은 프레임 구조를 사용하지 않을 경우, 터보 등화기의 전 역 반복이 3 회일 때 $8 \mathrm{~dB}$ 에서 $4 \times 10^{-4}$ 의 성능을 내며, 프레임 구조를 사용할 경우 전역 반복이 3 회일 때 $8 \mathrm{~dB}$ 에 서 $4 \times 10^{-5}$ 의 성능을 낸다. 결과적으로 본 논문에서 제 안하는 시스템은 프레임 구조를 사용하였을 경우, 프레임 구조를 사용하지 않았을 경우보다 더 좋은 성능을 내며, 프레임 구조를 사용할 경우 더 적은 터보 등화기의 반복 으로 프레임 구조를 사용하지 않는 경우와 유사한 성능 을 낼 수 있는 것을 확인하였다.

결론적으로, 제안하는 시스템은 동일 대역을 완전히 송신과 수신에 활용할 수 없는 TDD의 단점과 송수신을 동시에 하기 위하여 추가적인 주파수 대역이 필요한 $\mathrm{FDD}$ 의 단점을 동시에 극복하여 동일 대역에서 동시에 전 이중 통신을 할 수 있다.

\section{References}

[1] A. Thangaraj, R. K. Ganti, and S. Bhashyam, "Self-interference cancellation models for full-duplex wireless communications", in Proc. Int. Conf. Signal Process. Commun. (SPCOM), pp. 1-5, Bangalore, India, Jul. 2012.

[2] R. Esmailzadeh, M. Nakagawa, and E. A. Sourour, "Time-division duplex CDMA communications", IEEE Personal Commun., vol. 4, no. 2, pp. 51-56, Apr. 1997.

[3] L. Dong, "Open-loop beamforming for frequency-division duplex mobile wireless access", IEEE Trans. Veh. Technol., vol. 56, no. 4, pp. 1845-1849, Jul. 2007.

[4] J. I. Choi, M. Jain, K. Srinivasan, P. Levis, and S. Katti, "Achieving single channel, full duplex wireless communication", in Proc. 16th Annu. Int. Conf. Mobile Comput. Networking (Mobicom '10), pp. 1-12, Chicago, U.S.A., Sep. 2010.

[5] T. Riihonen, R. Wichman, "Analog and digital self-interference cancellation in full-duplex MIMO-OFDM transceivers with limited resolution in A/D conversion", Signals, Systems and Computers(ASILOMAR), 2012 Conference Record of the Forty Sixth Asilomar Conference on, pp. 45-49, Nov. 2012.

[6] N. Phungamngern, P. Uthansakul, and M. Uthansakul, "Digital and RF interference cancellation for single-channel full-duplex transceiver using a single antenna", Electrical Engineering/Electronics, Computer, Telecommunications and Information Technology(ECTI-CON), 2013 10th International Conference on, pp. 1-5, May 2013.

[7] Na Li, Weihong Zhu, and Haihua Han, "Digital interference cancellation in single channel, full duplex wireless communication", Wireless Communications, Networking and Mobile Computing(WiCOM), 2012 8th International Conference on, pp. 1-4, Sep. 2012.

[8] I. D. Chang, D. J. Park, and K. I. Kwon, "A self interference cancellation method in OFDM-based full duplex relay", in Proc. Korean Inst. Commun. Inform. Sci. (KICS) Fall Conf., Seoul, Korea, pp. 348-351, Nov. 2010. 
THE JOURNAL OF KOREAN INSTITUTE OF ELECTROMAGNETIC ENGINEERING AND SCIENCE. vol. 25, no. 2, Feb. 2014.

[9] Young Sik Han, Woon Geun Yang, "Adaptive feedback interference cancellation algorithm using correlations for adaptive interference cancellation system", $J$. The Korean Institute of Electromagnetic Engineering and Science, Korea, vol. 21, no. 4, pp. 427-432, Apr. 2010.

안 창 영

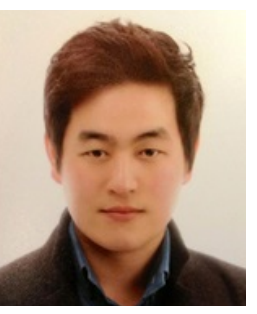

2013년 2월: 충북대학교 전자공학과 (공 학사)

2013년 3월 현재: 충북대학교 전자공학 과 석사과정

[주 관심분야] 무선통신시스템, 신호처리
[10] M. Tüchler, R. Koetter, and A. C. Singer, "Turbo equalization: principles and new results", Communications, IEEE Transactions on, vol. 50, no. 5, pp. 754-767, May 2002.

유 흥 균

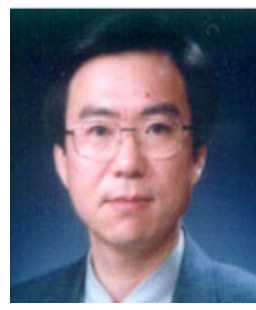

1988년 현재: 충북대학교 전자공학과 교 수

2002년 3월 2004년 2월: 충북대학교 컴 퓨터정보통신연구소 소장

1996년 현재: IEEE, IET 논문 심사위원

2002년: 한국전자파학회 학술상 수상

2008년: ICWMC 2008 국제학술대회 "Best

Paper Award" 수상

2009년: SPACOMM 2009 국제학술대회 "Best Paper Award" 수상 [주 관심분야] 무선통신시스템, 위성통신, $\mathrm{B} 4 \mathrm{G} / 5 \mathrm{G}$ 이동통신 시 스템, 통신회로 설계 및 통신 신호 처리 